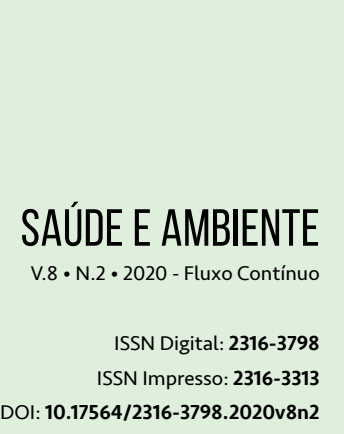

DOI: $10.17564 / 2316-3798.2020 v 8 n 2$

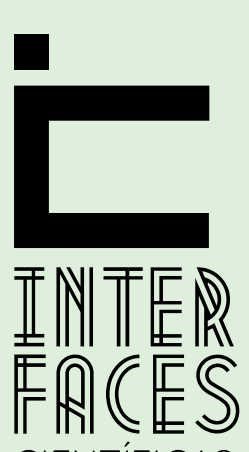

CIENTÍFICAS

\section{VARIAÇÃO SAZONAL DE PARÂMETROS FÍSICO-QUÍMICOS NA PORÇÃO ESTUARINA DO MUNICIPIO DE RAPOSA - MA}

SEASONAL VARIATION OF PHYSICO-CHEMICAL PARAMETERSIN

THE ESTUARY PORTION OF THE MUNICIPALITY OF RAPOSA - MA

VARIACIÓNESTACIONAL OELOSPARÁMETROS FÍSICO-QUUIIIICOSEN LAPORCIÓNESTUUARINA DEL MUNICIPIODE RAPOSA - MA

José Elias Ferreira do Nascimento ${ }^{1}$ Caíque Matheus do Nascimento Farias ${ }^{2}$ Maria Luiza Torres Pires ${ }^{3}$ Samara Aranha Eschrique ${ }^{4}$ Paula Cilene Alves da Silveira ${ }^{5}$

\section{RESUMO}

O sistema estuarino se destaca de outros da zona costeira por sua alta produtividade biológica, sendo um ambiente aberto, que está dominado por processos físicos, químicos e biológicos. A área de estudo abrange uma porção estuarina do Município de Raposa, a qual recebe influência das baías de São José e São Marcos, que compõem o Golfão Maranhense. 0 objetivo deste trabalho foi determinar a distribuição dos parâmetros físicos e químicos da água, relacionando com os períodos sazonais. As amostras das águas foram coletadas na superfície, realizadas em duas campanhas, abrangendo os períodos de chuva (maio/2017) e estiagem (novembro/2017), com sete pontos de coleta por campanha, totalizando 14 amostras de água, obtidas pela garrafa de van Dorn. Foram determinados os seguintes parâmetros hidroquímicos: profundidade local, temperatura, salinidade e condutividade; a transparência da água; o oxigênio dissolvido e a saturação do oxigênio; $\mathrm{pH}$, totais de sólidos suspensos (TSS) e turbidez. Os valores medianos nos períodos de chuva e estiagem, respectivamente, para os parâmetros medidos, foram: transparência de 3,4 e 4,5 m; temperatura 28,2 e $30^{\circ} \mathrm{C}$; salinidade 25,3 e $36,7 \mathrm{~g} \mathrm{~kg}^{-1}$; $\mathrm{pH} 7,8$ e 8,1 ; oxigênio dissolvido 2,5 e $5,0 \mathrm{mg} \mathrm{L}^{-1}$; saturação de OD 54,5 e 112,2\%; turbidez 13,1 e 36,0 UNT; TSS 42,4 e $136,3 \mathrm{mg} \mathrm{L}^{-1}$. A distribuição dos parâmetros físicos e químicos mostraram diferenças entre os períodos sazonais, principalmente relacionados com os aportes de água doce e marinha, com exceção da temperatura, que foi praticamente constante nos dois períodos.

\section{PALAVRAS-CHAVE}

Estuário. Golfão Maranhense. Propriedades Físicas e Químicas da Água. 


\section{ABSTRACT}

The estuarine system stands out from others in the coastal zone because of its high biological productivity, being an open environment that is dominated by physical, chemical and biological processes. The study area covers an estuarine portion of the Municipality of Raposa, from which it receives influence from the bays of São José and São Marcos, which make up the Golfão Maranhense. The objective of this work was to determine the distribution of the physical and chemical parameters of the water, relating to the seasonal periods. The water samples were collected on the surface in two campaigns, covering the rainy season (May / 2017) and dry season (November / 2017), with seven collection points per campaign, totaling 14 water samples obtained by the bottle of van Dorn. The following hydrochemical parameters were determined: local depth, temperature, salinity and conductivity; the water transparency $(\mathrm{m})$ was determined with a Secchi disc; dissolved oxygen (OD) oxygen saturation (\%); $\mathrm{pH}$, total suspended solids (TSS) and turbidity determined in the laboratory. The mean for the measured parameters was: transparency was 3.4 to $4.5 \mathrm{~m}$; temperature 28.2 at $30^{\circ} \mathrm{C}$; salinity 25.3 to $36.7 \mathrm{~g} \mathrm{~kg}-1$; $\mathrm{pH} 7.8$ to 8.1 ; dissolved oxygen 2.5 To $5.0 \mathrm{mg} \mathrm{L-1}$; saturation OD 54.5 to $112.2 \%$; turbidity 13.1 to 36.0 UNT; TSS 42.4 to $136.3 \mathrm{mg} \mathrm{L-1}$. The distribution of the physical and chemical parameters showed differences between the seasonal periods, mainly related to freshwater and marine inputs.

\section{KEYWORDS}

Estuary. Maranhense Gulf. Physical and Chemical Properties of Water.

\section{RESUMEN}

El sistema estuarino se destaca de otros de la zona costera por su alta productividad biológica, siendo un ambiente abierto, que está dominado por procesos físicos, químicos y biológicos. El área de estudio abarca una porción estuarina del Municipio de Raposa, de la cual recibe influencia de las bahías de San José y San Marcos, que componen el llamado Golfão Maranhense. El objetivo de este trabajo fue determinar la distribución de los parámetros físicos y químicos del agua, relacionando los períodos estacionales. Las muestras de aguas fueron recolectadas en la superficie realizadas en dos campañas, abarcando los períodos de lluvia (mayo / 2017) y seguía (noviembre / 2017), con siete puntos de recolección por campaña, totalizando 14 muestras de agua, obtenidas por la botella de van Dorn. Se determinaron los siguientes parámetros hidroquímicos: profundidad local, temperatura, salinidad y conductividad; la transparencia del agua (m) fue determinada con un disco de Secchi; el oxígeno disuelto (OD) saturación del oxígeno (\%); $\mathrm{pH}$, totales de sólidos suspendidos (TSS) y turbidez, determinados en laboratorio. La media para los parámetros medidos fue de: transparencia de 3,4 a 4,5m; 
temperatura 28,2 a $30^{\circ} \mathrm{C}$; salinidad 25,3 a 36,7 g kg-1; pH 7,8 a 8,1; oxígeno disuelto 2,5 a 5,0 mg L-1; saturación de OD 54,5 a 112,2\%; turbidez 13,1 a 36,0 UNT; TSS 42,4 a 136,3 mg L-1. La distribución de los parámetros físicos y químicos mostró diferencias entre los períodos estacionales.

\section{PALABRAS CLAVE}

Estuario. Golfão Maranhense. Propiedades físicas y químicas del agua.

\section{INTRODUÇ̧̃̃O}

Estuários são corpos de água caracterizados por mudanças temporais que ocorrem sobre um espectro de escalas de curto prazo (de hora em hora) e longo prazo (sazonal e interanual), sendo impulsionado principalmente por correntes de marés causados por forças meteorológicas ou por descargas fluviais. Dependem do período de chuva e seca, sua dinâmica também depende das taxas de precipitação, evaporação e altura de marés (ANEESHKUMAR; SUJATHA, 2012).

São ambientes costeiros, semifechados, de pequenas profundidades, onde apresentam uma livre conexão com o mar aberto, por onde a água do mar é gradativamente diluída pela água doce proveniente da drenagem terrestre (PRITCHARD, 1967; CARTER, 1988). Segundo Silva e Koening (1993), por possuírem características ambientais únicas e que são fundamentais para o ciclo de vida de diversas espécies; tornam-se áreas preferenciais de formação de núcleos urbanos, por conta de sua natureza facilmente exploráveis, em razão dos vários recursos que oferecem.

O litoral maranhense é relativamente extenso, caracterizado por grande número de pequenos estuários recortados numa planície baixa. Nesse contexto encontra-se o sistema estuarino do município da Raposa que apresenta aproximadamente $64 \mathrm{~km}^{2}$ de área, localizado a nordeste de São Luís, a oeste da baía de São Marcos e a leste da baía de São José (SANTOS et al., 2011).

Por constituírem um ambiente altamente dinâmico, as variáveis físicas e químicas sofrem constantes modificações, a partir de fatores naturais e antrópicos, onde a caracterização de um estuário é fundamental para o entendimento dos processos que ocorrem na região, que fornecem bases para conservação e uso sustentável destes ambientes (D’AQUINO et al., 2011).

O município de Raposa, considerando toda complexidade contida nesses ecossistemas, apresenta uma escassez de estudos que retratam suas características ambientais básicas e que auxiliam no entendimento sobre os diversos corpos de águas que estão inseridos nessa região, podendo-se citar trabalhos como o de Dias e colaboradores (2006), que analisaram as feições geomorfológicas dos diversos ambientes inseridos no município, o de Santos e colaboradores (2014) que analisaram a dinâmica da população da espécie de Anomalocardia brasiliana (Mollusca, Bivalvia, Veneridae) no estuário do rio Paciência e o de Meneghetti e Kux (2014) que realizou mapeamento da cobertura da terra na área natural do município de Raposa, utilizando imagens do sensor WorldView-II. 
Portanto com o intuito de ampliar os conhecimentos sobre os principais fatores ambientais hidrológicos, este estudo objetiva determinar a distribuição dos parâmetros físicos e químicos da água, no sistema Estuarino de Raposa-MA, considerando as variações sazonais e espaciais.

\section{MATERIAIS E MÉTODOS}

\section{1 ÁREA DE ESTUDO}

A área de estudo deste trabalho abrange uma porção do Sistema Estuarino do Rio Paciência, no município de Raposa (FIGURA1), que recebe influência do Golfão Maranhense, por meio dos canais de comunicações com as baías de São Marcos (oeste) e São José (leste).

Figura 1 - Localização da área de estudo na porção estuarina do município de Raposa, identificando os pontos de coleta

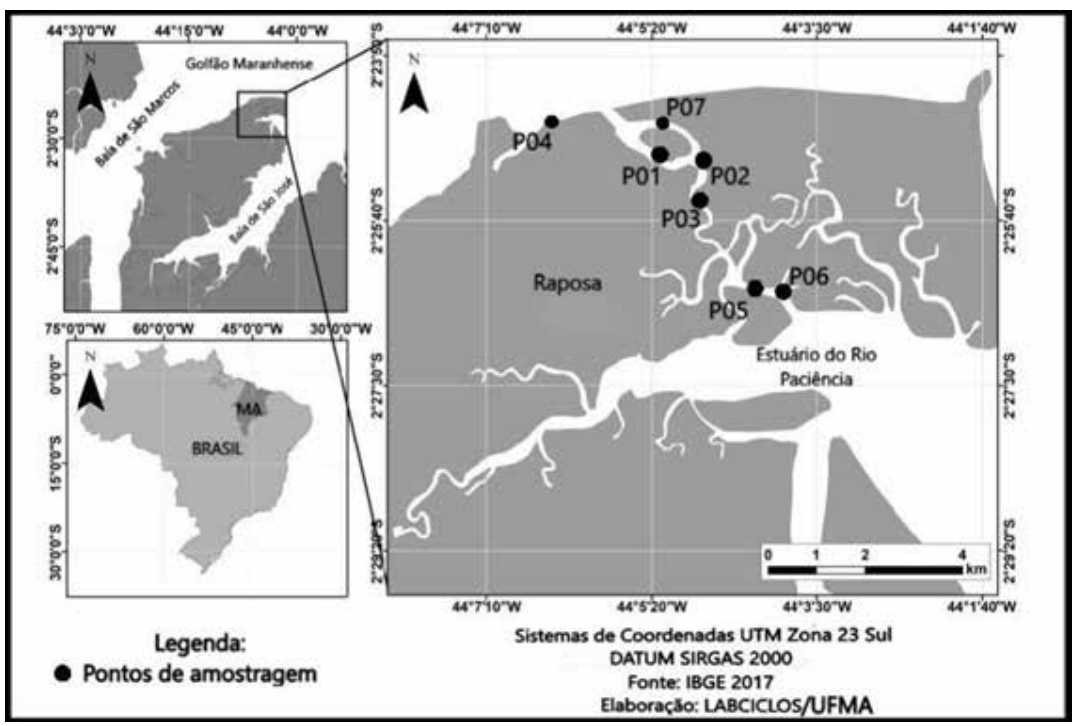

Fonte: Dados da Pesquisa

O Município da Raposa está localizado no quadrante nordeste da ilha do Maranhão entre as coordenadas de $02^{\circ} 25^{\prime} 22^{\prime \prime} S$ e $44^{\circ} 05^{\prime} 21^{\prime \prime} W$ (FERREIRA, 2005). Possui aproximadamente 26.327 habitantes segundo o Instituto Brasileiro de Geografia e Estatística (IBGE, 2017) e cerca de $60 \mathrm{~km}^{2}$ do centro de São Luís, capital do estado do Maranhão. É limitado ao norte pelo Oceano Atlântico; ao sul pelos municípios de Paço Lumiar e de São José de Ribamar; a leste pela ilha de Cururupu e a baía de São Marcos e a oeste pelo município de São Luís. 
Para esse estudo foram realizadas duas campanhas de amostragens, abrangendo dois períodos sazonais chuva (maio/2017) e estiagem (novembro/2017). Foram coletadas amostras de água em sete pontos por campanha, totalizando quatorze amostras coletadas na camada subsuperficial ( 0 $0,5 \mathrm{~m}$ ) da coluna de água.

As amostras de água foram obtidas com auxílio da garrafa de van Dorn de 5,0 L. Posteriormente, as amostras foram recolhidas em frascos plásticos com volume de $500 \mathrm{~mL}$, separadas em algumas subalíquotas, uma para determinações in situ e as demais sendo refrigeradas em isopor com gelo, para determinações em laboratório.

\subsection{ANÁLISES FÍSICA E QUUIMICA}

Os seguintes parâmetros hidroquímicos foram determinados in situ: a profundidade local, temperatura, salinidade e condutividade, por meio do instrumento Conductivity, Temperature and Depth (CTD) modelo EX02 - YSI 108; e a transparência da água, determinada com o coeficiente de extinção da luz apresentado por Poole e Atkins (1929), a partir da medida de profundidade de desaparecimento do disco de Secchi.

Em laboratório, foram determinados: o oxigênio dissolvido (OD), obtido pelo método de Winkler conforme descrito em Strickland e Parsons (1972); os cálculos de saturação de oxigênio dissolvido, calculados com o auxílio das tabelas de Aminot e Chaussepied (1983); o pH da água, medido com o pHmetro (PHM240-MeterLab); o total de sólidos suspensos (TSS), determinados por técnica gravimétrica, segundo as metodologias descritas em Strickland e Parsons (1972) e APHA (2012); a turbidez da água foi medida com o turbidímetro de marca TECNOPON TB-1000 e os resultados foram expressos em Unidades Nefelométricas de Turbidez (UNT).

\subsection{ANÁLISES ESTATÍSTICAS}

O teste estatístico utilizado foi a Análise de Componentes Principais (ACP), para verificar as relações da sazonalidade sobre os parâmetros físicos e químicos nas águas estuarinas. 0 teste estatístico foi realizado com auxílio do programa PAleontological STatistics PAST 3.25 - 2019 (HAMMER et al., 2001).

\section{RESULTADOS}

Os valores mínimos, máximos e desvios padrão dos parâmetros físicos e químicos estudados neste trabalho são apresentados na Tabela 1.

A profundidade de coleta local (FIGURA 2A) e a transparência da água (FIGURA 2B) variaram entre as campanhas de chuva e estiagem, também entre os pontos de coleta (TABELA 1). 
Figura 2 - Distribuição superficial dos parâmetros: (A) Profundidade de coleta (B) Transparência da água (m); (C) Temperatura ( $\left.{ }^{\circ} \mathrm{C}\right)$; (D) Salinidade ( $\mathrm{g} \mathrm{kg}-1$ ), na porção estuarina do município de Raposa
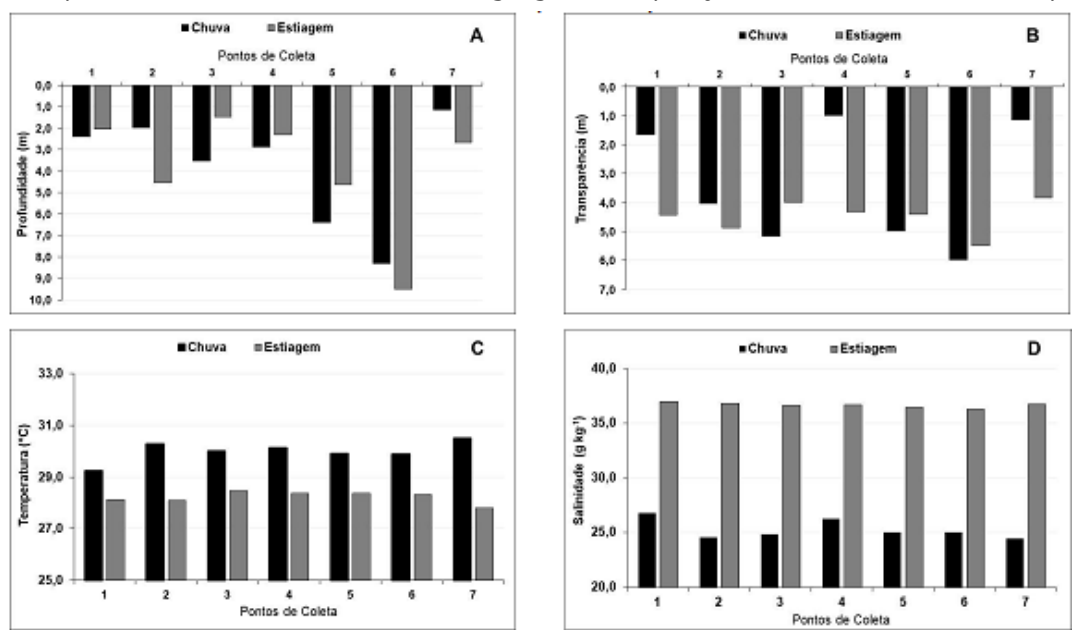

Fonte: Dados da Pesquisa

A temperatura (FIGURA 2C) foi homogênea, com média de $29,9^{\circ} \mathrm{C}$ no período chuvoso e $28,2^{\circ} \mathrm{C}$ no período de estiagem.

Tabela 1 - Parâmetros físicos e químicos da água nos períodos sazonais, chuvoso e estiagem na porção estuarina do município de Raposa

\begin{tabular}{|c|c|c|c|c|c|c|c|c|c|c|}
\hline Período & Prof. Local & Transp. & Temp. & $\begin{array}{l}\text { Sal. } \\
\text { g.kg-1 }\end{array}$ & pH & $\begin{array}{l}\text { OD } \\
\underset{1}{\mathrm{mg} \cdot \mathrm{L}^{-}}\end{array}$ & 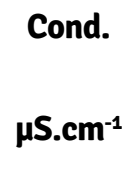 & $\begin{array}{l}\text { Turb. } \\
\text { UNT }\end{array}$ & $\begin{array}{c}\text { TSS } \\
\text { mg. } \mathrm{L}^{-1}\end{array}$ & $\begin{array}{l}\text { OD } \\
\%\end{array}$ \\
\hline \multicolumn{11}{|l|}{ Chuvoso } \\
\hline Mínimo & 1,1 & 1,0 & 29,2 & 24,5 & 7,7 & 2,1 & 38,5 & 3,5 & 35,9 & 45,4 \\
\hline Máximo & 8,3 & 6,0 & 30,5 & 26,8 & 8,0 & 2,7 & 41,6 & 38,0 & 70,8 & 57,6 \\
\hline $\begin{array}{l}\text { Desvio } \\
\text { Padrão }\end{array}$ & 2,6 & 2,1 & 0,4 & 0,9 & 0,1 & 0,2 & 1,2 & 11,5 & 12,8 & 4,2 \\
\hline $\mathrm{n}$ & 7 & 7 & 7 & 7 & 7 & 7 & 7 & 7 & 7 & 7 \\
\hline \multicolumn{11}{|l|}{ Estiagem } \\
\hline Mínimo & 1,5 & 3,8 & 27,8 & 36,3 & 8,0 & 3,8 & 54,6 & 19,0 & 115,3 & 85,4 \\
\hline Máximo & 9,5 & 5,5 & 28,5 & 37,0 & 8,2 & 9,3 & 55,5 & 75,0 & 204,2 & 208,4 \\
\hline
\end{tabular}


Prof. Local Transp. Temp. Sal. pH OD Cond. Turb. TSS OD

Período

m

m

${ }^{\circ} \mathbf{C} \quad \mathbf{g} \cdot \mathbf{k g}^{-1}$ mg.t-

$\mu \mathrm{S} . \mathrm{cm}^{-1}$ UNT $\mathrm{mg} . \mathrm{L}^{-1} \quad \%$

Desvio

Padrão

$$
2,8
$$

0,6

$0,2 \quad 0,2$

$0,1 \quad 1,9$

0,3

18,5

31,0

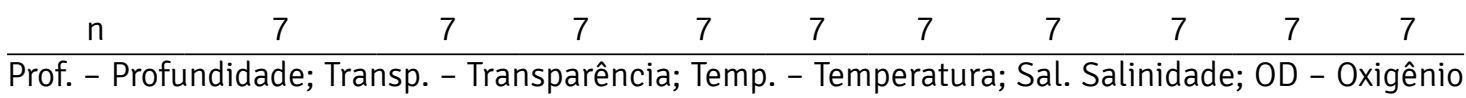
Dissolvido, Cond. - Condutividade; Turb. - Turbidez; TSS - Totais de Sólidos Suspensos.

Fonte: Dados da Pesquisa

A salinidade (FIGURA 2D) mostrou uma distribuição distinta entre os períodos sazonais, mas homogênea entre os pontos de coleta, com valor médio por período de 25,3 e $36,7 \mathrm{~g} \mathrm{~kg}^{-1}$ para chuva e estiagem, respectivamente. Os teores de oxigênio dissolvido (FIGURA 3A) foram menores no período chuvoso, com média de $2,5 \mathrm{mg} \mathrm{L}^{-1}$ e maiores na estiagem, média de $5,0 \mathrm{mg} \mathrm{L}^{-1}$. Os valores percentuais de saturação de oxigênio (FIGURA 3A) seguiu o mesmo padrão de distribuição observado para o oxigênio dissolvido, apresentando valores, variando de baixa saturação a saturado no período de chuva, melhorando para saturado a supersaturado na estiagem.

Os valores de $\mathrm{pH}$ sempre se mostraram básicos em todos os pontos de coleta (FIGURA 3C). As médias sazonais oscilaram entre 7,68 e 8,10 chuvoso e estiagem, respectivamente.

Figura 3 - Distribuição superficial dos parâmetros: (A) Oxigênio Dissolvido (mg L-1) e percentual de saturação de OD; (B) Potencial Hidrogeniônico; (C) Totais de Sólidos Dissolvidos (mg L-1); (D) Turbidez (UNT), na porção estuarina do munícipio de Raposa

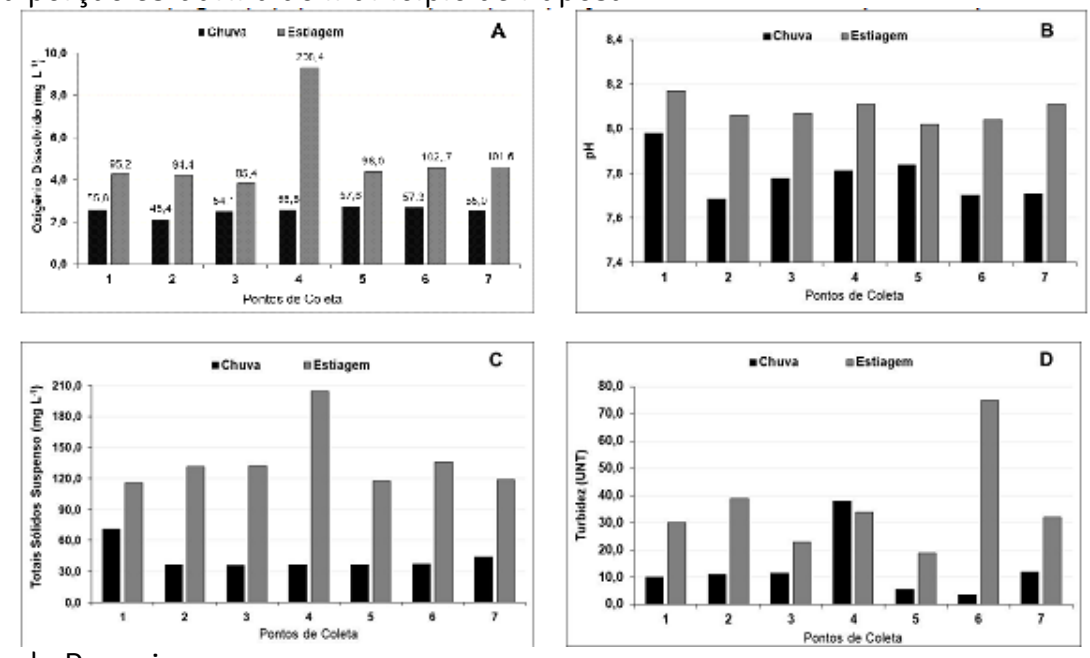

Fonte: Dados da Pesquisa 
O TSS apresentou os menores valores no período chuvoso, com média de $42,3 \mathrm{mg} \mathrm{L}^{-1}$, já para estiagem houve um aumento nas concentrações, com média de 136,9 $\mathrm{mg} \mathrm{L}^{-1}$ (FIGURA 3C).

As concentrações de turbidez variaram bastante entre as campanhas e entre os pontos de coleta na porção estuarina, com médias de 13,1 UNT para o período chuvoso e 36,0 para a estiagem.

As correlações obtidas pela a Análise dos Componentes Principais (ACP) explicaram $81,7 \%$ da variação dos dados nos dois primeiros fatores (FIGURA 4). 0 componente 1 mostrou que os parâmetros: salinidade, condutividade, $\mathrm{pH}$, oxigênio dissolvido, percentual de saturação de oxigênio e totais de sólidos em suspensão se correlacionaram positivamente, representando mais de $65 \%$ de todos os dados.

A Análise dos Componentes Principais (ACP) explicaram $81,8 \%$ da variação dos dados nos dois primeiros fatores (FIGURA 4), sendo que o fator 1 explicou $65,4 \%$ e o fator 2 explicou $16,4 \%$ da distribuição dos dados.

Figura 4 - Análises de Componentes Principais (ACP), para os parâmetros físicos e químicos sobre os dois períodos sazonais: chuvoso (PC); estiagem (PE)

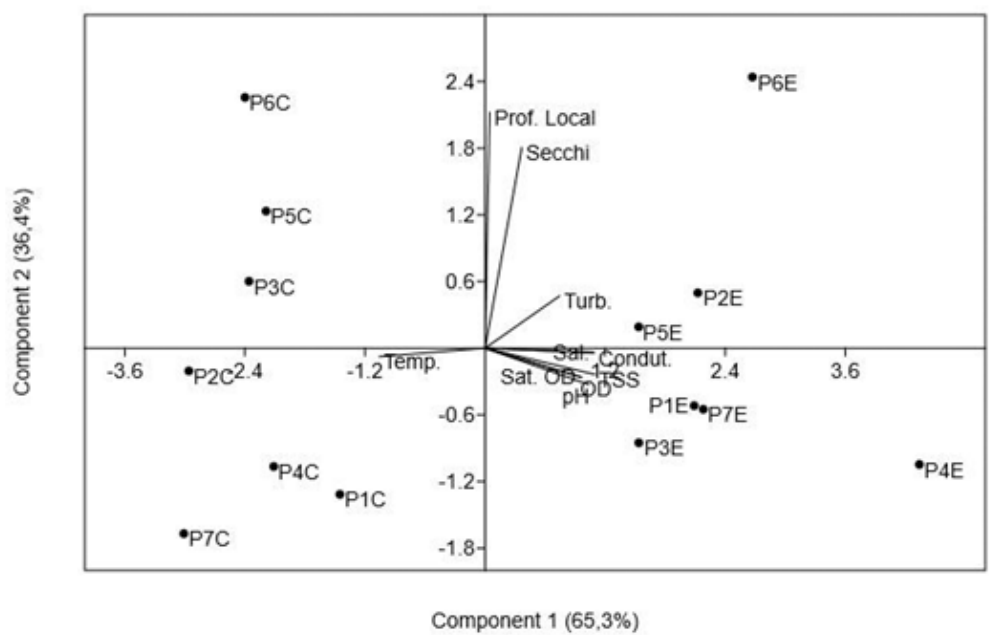

Prof. Local - Profundidade Local; Secchi - Transparência; Temp. - Temperatura; Sal. Salinidade; OD - Oxigênio Dissolvido, Condut. - Condutividade; Turb. - Turbidez; TSS - Totais de Sólidos Suspensos Fonte: Dados da Pesquisa

\section{DISCUSSÃO}

No sistema estuarino do município de Raposa alguns parâmetros hidroquímicos mostraram consideráveis variações tanto sazonais (período chuvoso e de estiagem), quanto longitudinais (mais próximos ao mar e mais distantes dele), levando em conta a dinâmica de marés, a pluviosidade e a 
topografia locais. Tundisi (1970) afirma que normalmente algumas variações ocorridas em sistemas estuarinos, podem estar relacionadas com fatores climatológicos e/ou oceanográficos, como a precipitação pluviométrica e com alguns movimentos sazonais da água.

A distribuição da profundidade nos locais de coleta deste estudo foi variável, tanto entre os pontos, como entre as campanhas de amostragens, indicando que este canal estuarino é bastante dinâmico. Apesar disso, as médias apresentadas nos dois períodos sazonais foi bastante semelhante, com uma variação de $\pm 0,1 \mathrm{~m}$ entre os períodos.

Normalmente, os ambientes estuarinos são considerados rasos, devido aos constantes aportes continentais e marinhos a que estão sujeitos. Na porção estuarina do município de Raposa não foi diferente, pois este ambiente recebe importantes contribuições de aportes marinhos, oriundos das baías de São Marcos e São José, além das contribuições das margens do canal, que apresenta áreas de manguezal e de dunas. Este ambiente também está sujeito a dinâmica de macromaré, que tem amplitudes maiores de $6,0 \mathrm{~m}$ na região, modificando a geomorfologia de fundo e promovendo a ressuspensão de sedimentos.

A transparência da água na área de estudo mostrou valores menores no período chuvoso, em comparação com o período de estiagem. Isto acontece devido ao maior aporte de materiais lixiviados na água, comuns durante o período chuvoso, que interferem na penetração de luz na camada superficial. A transparência da água geralmente é influenciada pela incidência solar, entrada de matérias carreadas pela bacia de drenagem, processos de ressuspensão e/ou fatores biológicos como, por exemplo, um bloom algal.

Alguns pontos do ambiente estuarino mostraram valores de transparência que alcança até a camada de fundo (pontos 2 e 3 - chuva; pontos 1, 2, 3, 4 e 7 - estiagem), sendo bastante favorável para a biota aquática local, que não é limitada por este parâmetro.

A distribuição superficial da temperatura da água apresentou uma discreta variação sazonal, tendo uma amplitude de apenas $1,8^{\circ} \mathrm{C}$ entre os valores médios por períodos estudados, característica de regiões equatoriais, que apresentam elevadas temperaturas durante todo o ano, o que favorece os processos de evaporação.

Gomes (2017) observou que as maiores temperaturas superficiais das águas no estuário do Arraial (MA) foram durante o período de estiagem, devido a menor precipitação pluviométrica, consequentemente, uma maior evaporação, elevando a temperatura. No entanto, para o sistema estuarino de Raposa, a temperatura foi maior no período chuvoso, mostrando comportamento oposto ao observado pela autora. Tal fato deve estar relacionado com o horário de coleta, que no período de chuva compreendeu das 10:00 às 13:00 horas, horário de maior incidência solar, já na estiagem foi das 08:00 às 11:30 horas.

Outros fatores relevantes foram a profundidade da lâmina d'água e a condição de maré, que durante a campanha de chuva, o intervalo de coleta aconteceu próximo do pico da preamar, enquanto que no período de estiagem, foi na condição de maré vazante, modificando a profundidade local de coleta e os tipos de contribuições de aportes de água no estuário, que interferem na temperatura da água.

As medidas de salinidade variaram bastante entre as duas campanhas, indicando que a porção estuarina tem uma alta amplitude entre o período chuvoso e de estiagem. No período chuvoso a salinidade manteve características polihalino, apresentada pela maioria das águas estuarinas das 
regiões tropicais, tal parâmetro pode estar sendo influenciado pela pluviosidade e aporte fluvial, que gradativamente diluem as águas salinas dentro do sistema estuarino.

As altas salinidades observadas durante o período de estiagem mostraram que a região em estudo recebe forte influência das contribuições marinhas, com registro de todos os seus valores neste período maior que a média dos oceanos, que é de $35 \mathrm{~g} \mathrm{~kg}^{-1}$ (PRITCHARD, 1967), caracterizando o estuário como euhalino.

Os teores de oxigênio dissolvido foram menores no período chuvoso, com concentrações sempre menor do 3,0 mg L-1, o que pode comprometer as atividades biológicas do sistema estuarino e provocar condições de estresse químico nos organismos que utilizam este gás. As baixas concentrações de OD neste período podem estar relacionadas com as maiores demandas bioquímicas pela biota, maior quantidade de carga orgânica e trocas gasosas no ambiente aquático.

Figueiredo e colaboradores (2006), em estudos no complexo estuarino de Itamaracá-PE, relacionaram os maiores valores de OD com a maré. Eles também afirmam que isso ocorre devido à turbulência gerada pelas correntes de marés, visto que na segunda campanha as coletas foram feitas sobre influência da maré de sizígia, enquanto a primeira campanha foi realizada durante influências da maré de quadratura e relacionados à agitação dos ventos, que são maiores durante o período onde foi realizada a segunda campanha (estiagem), podendo oxigenar ou retirar OD da água, corroborando com o que foi verificado neste estudo.

Eschrique (2011) analisou que o nível de oxigênio dissolvido em águas naturais é, com frequência, uma indicação direta de qualidade de água, uma vez que este gás é essencial para a subsistência de peixes e outras vidas aquáticas heterotróficas e auxilia na decomposição natural da matéria orgânica.

Os valores de $\mathrm{pH}$ na distribuição superficial presente no atual estudo, apresentaram um caráter levemente alcalino, embora os maiores valores foram observados no período de estiagem, mostrando um comportamento atípico, onde esse padrão de distribuição pode estar relacionado com a renovação das águas estuarinas pela entrada da maré, que traz consigo água marinha que é ligeiramente básica (DONEY, 2006), aumentando gradativamente de acordo com a amplitude de maré, principalmente quando se encontra sobre a influência das marés de sízigia, como visto nesse estudo. A resolução CONAMA n $n^{\circ}$ 357/2005 recomenda $\mathrm{pH}$ entre 6,5 e 9,0 para água salina, podendo haver uma mudança natural do $\mathrm{pH}$ de $\pm 0,2$, para água salobra.

A distribuição dos teores Totais de Sólidos Suspensos (TSS) foram menores na estação chuvosa, o que difere de outros estuários tropicais; visto que a quantidade de sólidos em suspensão é maior quando há um aumento de aporte terrestre (NIENCHESKI, 2015).

As baixas concentrações de TSS observadas nesse período podem estar associadas com a mudança de tamanho das frações em suspensão de particulada para dissolvida, devido à maior competência de transportes que ocorre nos rios, durante o período de chuvoso, levando a maior carga das partículas em suspensão para a zona costeira adjacente.

Houve um aumento nos valores no período de estiagem, o que pode estar associado a dinâmica local, devido à atuação das marés, ocasionando a remobilização de sedimentos. Vale ressaltar que os maiores valores encontrados ocorreram onde a influência marinha foi maior (P04 e P06), que ficam 
próximo às desembocaduras, apresentando ótimas condições para a ressuspensão dos sedimentos de fundo e/ou das margens do canal, quando a corrente salina se arrasta junto ao fundo, colocando-os novamente na coluna de água.

Em trabalho realizado por Corrêa (2016), essa variação sazonal foi observada ao estudar o estuário do rio Mearim-MA, apresentando valores de $121,97 \mathrm{mg} \mathrm{L-1}$ no período chuvoso e $300,06 \mathrm{mg} \mathrm{L-1}$ na estiagem, associando os valores mais elevados no período de estiagem principalmente pelo fluxo e refluxo das marés.

A turbidez da água também mostrou distribuição semelhante a observada para o TSS, com os menores valores no período chuvoso e maiores valores no período de estiagem. As maiores concentrações medidas se devem à maior quantidade de TSS, em razão da remobilização de materiais de fundo, devido ao fluxo e refluxo de maré. Tendo em vista que tais registros foram feitos sob condição de sizígia, o que podem estar relacionados à maior amplitude de maré e, portanto, ao maior movimento que a água sofre no estuário.

Já no período chuvoso, em condição de quadratura, as concentrações foram bem menores, tanto na baixamar, quanto na preamar, pela menor amplitude de maré e menor movimentação da água. 0 ponto 4 onde foi registrado o maior valor, o que pode estar associado com a presença de uma barreira arenosa que ocorre neste ponto, devido a entrada da maré, o que causa a ressuspensão de sedimento.

A turbidez de uma amostra de água é definida como o grau de atenuação de intensidade, que um feixe de luz sofre ao atravessá-la (CETESB, 2003); provocando a redução de intensidade dos raios luminosos que penetram no corpo de água, atuando decisivamente nas características do ecossistema presente. Ela é um parâmetro chave no monitoramento da qualidade de águas superficiais, devido à sua relação com a concentração de material em suspensão e sua influência na ecologia do ambiente aquático (GÖRANSSON et al., 2013). Segundo os padrões de qualidade de água, estabelecidos na Resolução CONAMA n 357/2005, os valores de turbidez não excederam os valores máximos permitidos (de até 100 UNT) por esta resolução.

De acordo com os resultados de análises de componentes principais, o fator 1 explica a variância dos parâmetros TSS, OD, Salinidade, Condutividade, pH, Saturação de oxigênio e turbidez apresentaram uma boa correlação entre si, evidenciando que estes parâmetros são influenciados pelo maior ou menor aporte de águas doce e salina no ambiente, de acordo com o período sazonal.

O fator 2 explica a variância dos parâmetros Profundidade Local e Transparência, indicando que estas variáveis não são explicadas pelos mesmos agentes influenciadores dos demais parâmetros, sendo sua distribuição impulsionada pelo fluxo e refluxo das marés, que pela pequena profundidade local, proporcionam maior perturbação de fundo e/ou maior erosão das margens, contribuindo como fonte de materiais sedimentar para o canal estuarino, modificando sua geomorfologia de fundo.

\section{CONSIDERAÇÕES FINAIS}

Os parâmetros físicos e químicos estudados mostraram que o sistema estuarino do município da Raposa é um ambiente raso, com temperaturas elevadas, típicos de regiões de baixa latitude, bastante dinâmico e fortemente influenciado pelas entradas das marés. 
A salinidade e a condutividade apresentaram controle climático na distribuição dos seus valores, apresentando águas salobras durante o período de chuva e salinas durante a estiagem, com os menores valores relacionados com a precipitação e descarga fluvial e os maiores valores com as contribuições marinhas.

$\mathrm{O}$ pH foi básico nos dois períodos, mantendo-se próximo ao pH marinho. 0 oxigênio dissolvido e o percentual de saturação de OD indicaram pouca disponibilidade deste gás na água, durante a campanha de chuva, podendo trazer prejuízos para a biota aquática nesse período. No entanto, o ambiente melhora sua oxigenação, durante o período de estiagem, restabelecendo o seu equilíbrio químico, devido à renovação de suas águas pela maré.

O TSS e a turbidez variaram bastante entre as campanhas, principalmente sendo relacionados com os fluxos e refluxos de marés, que promovem a ressuspensão de materiais na coluna d'água.

É importante ressaltar que o conhecimento dos parâmetros ambientais nos estuários dessa região em diferentes períodos sazonais e temporal é de suma importância, pois contribuem para uma melhor avaliação ambiental local. Este estudo será em parte, uma contribuição para consolidar e fomentar uma base de dados e de conhecimento técnico e científico, com propósito de tornar públicas essas informações aos tomadores de decisão da região.

\section{REFERÊNCIAS}

APHA - American Public Health Association. Standard methods for the examination of water and wastewater. $22^{\text {nd }}$ ed. Washington: American Public Health Association Pub, 2012

AMINOT, A.; CHAUSSEPIED, M. Manuel des analyses chimiques en milieu marin. Brest: CNEXO, 1983.

ANEESHKUMAR, N.; SUJATHA, C. H. Biomarker pigment signatures in Cochin back water system-a tropical estuary south west coast of India. Estuar. Coast. Shelf S., v. 99, p. 182-190, 2012.

CARTER, G. W. R. Coastal environments: an introduction to the physical, ecological and cultural systems of coastlines. London: Academic Press, 1988.

CETESB - Companhia Ambiental do Estado de São Paulo. Relatório de qualidade das águas interiores do Estado de São Paulo 2002/ CETESB. São Paulo: CETESB, 2003.

CORRÊA, M. C. Hidrogeoquímica dos sólidos totais em suspensão no estuário do rio Mearim. 2016. 111f. Trabalho de Conclusão de Curso (Graduação em Oceanografia) - Universidade Federal do Maranhão, São Luís-MA, 2016.

D’AQUINO, C. A. et al. Caracterização oceanográfica e do transporte de sedimentos em suspensão no estuário do Rio Mampituba, SC. Rev. Bras. Geof., v. 29, n. 2, p. 217-230, 2011. 
DIAS, L. J. B. et al. Geomorfologia e análises ambientais do sítio urbano de Raposa (MA). Simpósio Nacional de Geomorfologia, 6, 2006. Anais..., Goiânia-GO, 2006.

DONEY, S. C. Perigos da acidificação dos oceanos. Sci. Am. Brasil, v. 47, n. 4, p. 58-65, 2006

ESCHRIQUE, S. A. Estudo do balanço biogeoquímico dos nutrientes dissolvidos principais como indicador da influência antrópica em sistemas estuarinos do nordeste e sudeste do Brasil. 2011. 254f. Tese (Doutorado em Ciências - Oceanografia Química e Geológica) - Universidade de São Paulo, São Paulo, 2011.

FERREIRA, A. G. Técnicas de sensoriamento remoto para monitoramento ambiental com aplicações em recursos pesqueiros no atlântico tropical. 2005. 169f. Dissertação (Mestrado em Ciências Marinhas Tropicais) - Universidade Federal do Ceará, Fortaleza-CE, 2005.

FIGUEIREDO, J. A. et al. Hidrologia e biomassa fitoplanctônican nas barras Orange e Catuama (canal de Santa Cruz) em Itamaracá-PE: variação nictemeral. Arq. Ciên. Mar., v. 39, p. 5-17, 2006.

\section{GOMES, C. K. S. Estudos dos nutrientes dissolvidos no complexo estuarino do Arraial -}

Maranhão. 2017. 38f. Trabalho de conclusão de curso (Graduação em Oceanografia) - Universidade Federal do Maranhão, São Luís-MA, 2017.

GÖRANSSON, G. et al. Variation in the turbidity with precipitation and flow in a regulated river system - river Göta Älv, SW Swedem. Hidrol. Earth Syst. Sci., v. 17, n. 7, p. 2529-2542, 2013.

IBGE - Instituto Brasileiro de Geografia e Estatísitica, 2017. Disponível em: https://cidades.ibge.gov. br/brasil/se/panorama. Acesso em: 21 mar. 2019.

MENEGHETTI, G. T.; KUX, H. J. H. Mapeamento da cobertura da terra no município de Raposa (MA) utilizando imagens Worldview-II, o aplicativo interimage e mineração de dados. Rev. Bras. Cartograf., v. 66, n. 2, p. 365-377, 2014.

NIENCHESKI, L. F. H. Propriedades químicas da água de mar. In: CASTELLO, J. P.; KRUG, L. C. (Org.). Introdução às Ciências do Mar. Pelotas: Editora Textos, 2015.

HAMMER, Ø. et al. PAST: paleontological statistics software package for education and data analysis. Palaeontol. Electr., v. 4, n. 1, p. 1-9, 2001.

POOLE, H. H.; ATKINS, W. R. G. Photo-electric measurements of submarine illumination throughout the year. J. Mar. Biol. Assoc. U.K, v. 16, n. 1, p. 297-324. 1929. 
PRITCHARD, D. W. What Is an Estuary: Physical Viewpoint. In: AAAS - American Association for the Advancement of Science. Estuaries. Washington DC: AAAS. 1967.

SANTOS, J. J. S. et al. Dinâmica da população de Anomalocardia brasiliana (Mollusca, Bivalvia, Veneridae) no estuário do Rio Paciência, no município da Raposa, estado do Maranhão. An. IGEO, v. 37, n. 1, p. 61-69, 2014.

SANTOS, P. V. C. J. et al. Perfil socioeconômico de pescadores do município da Raposa, Estado do Maranhão. Rev. Bras. Eng. Pesca, v. 6, n. 1, p. 1-14, 2011.

SILVA, I. G.; KÖENING, M. L. Variação sazonal da densidade fitoplanctônica no estuário do rio Paripe, Itamaracá - Pernambuco, Brasil. Arq. Biol. Tecnol., v. 36, p. 645-658, 1993.

STRICKLAND, J. D. H.; PARSONS, T. R. A practical handbook of seawater analysis. $2^{\text {nd }}$ Ed. Ottawa: Fisheries Research Board of Canada, 1972.

TUNDISI, J. G. O. O plâncton estuarino. Contr. Avul. Instituto Oceanog., Univ. São Paulo, v. 19, p. 1-12, 1970. 
1 Acadêmico do Curso de Graduação em Oceanografia, Universidade Federal do Maranhão - UFMA.

E-mail: ferreira.joseelias451@hotmail.com

2 Acadêmico do Curso de Graduação em Oceanografia, Universidade Federal do Maranhão - UFMA.

E-mail: caique_matteus@hotmail.com

3 Acadêmica do Curso de Graduação em Oceanografia, Universidade Federal do Maranhão - UFMA.

E-mail: malutoresp@gmail.com

4 Doutora em Oceanografia Química e Geológica; Professora do Departamento de Oceanografia e Limnologia, Universidade Federal do Maranhão - UFMA.

E-mail: samara.eschrique@gmail.com

5 Doutora em Oceanografia; Professora do Departamento de Oceanografia e Limnologia, Universidade Federal do Maranhão - UFMA. E-mail: paulacilene@yahoo.com.br

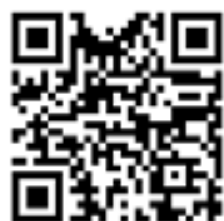

A autenticidade desse artigo pode ser conferida no site https://periodicos. set.edu.br

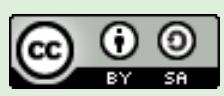

Este artigo é licenciado na modalidade acesso abertosob a Atribuição-Compartilhalgual CC BY-SA

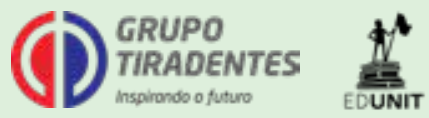

